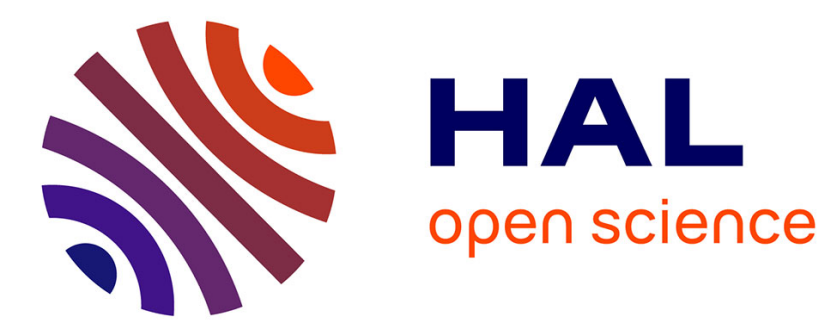

\title{
Time-frequency analysis applied to door slam sound quality problems
}

\author{
H. van Der Auweraer, K. Wyckaert, W. Hendricx
}

\section{To cite this version:}

H. van Der Auweraer, K. Wyckaert, W. Hendricx. Time-frequency analysis applied to door slam sound quality problems. Journal de Physique IV Proceedings, 1994, 04 (C5), pp.C5-1379-C5-1382. 10.1051/jp4:19945307 . jpa-00253022

\section{HAL Id: jpa-00253022 https://hal.science/jpa-00253022}

Submitted on 1 Jan 1994

HAL is a multi-disciplinary open access archive for the deposit and dissemination of scientific research documents, whether they are published or not. The documents may come from teaching and research institutions in France or abroad, or from public or private research centers.
L'archive ouverte pluridisciplinaire HAL, est destinée au dépôt et à la diffusion de documents scientifiques de niveau recherche, publiés ou non, émanant des établissements d'enseignement et de recherche français ou étrangers, des laboratoires publics ou privés. 


\title{
Time-frequency analysis applied to door slam sound quality problems
}

\author{
H. VAN DER AUWERAER, K. WYCKAERT and W. HENDRICX
}

LMS International, Interleuvenlaan 68, Leuven, Belgium

\begin{abstract}
Spectral analysis of non-stationary phenomena using traditional, segment averaged, discrete Fourier transform techniques suffers from limitations related to the trade-off between temporal and spectral resolution. These limitations are inherently due to the assumption of signal stationarity over an observation interval of fixed duration.

In case frequency components occur in widely different frequency bands, an alternative technique, based upon the Wavelet transform, yields results with a temporal resolution which is inversely proportional to the analysis frequency.

The issue of non-stationary spectral analysis is discussed at the hand of a sound quality problem related to a door slam. It is shown how the Wavelet analysis allows to identify the critical time instances and hence the critical physical phenomena responsible for the problem.
\end{abstract}

\section{INTRODUCTION}

The estimation of the frequency spectrum is a very important tool in the analysis of signal and system characteristics. With today's powerful data processing systems, where the estimation is in general implemented by methods based on the (discrete) Fourier transform, this operation is fast and straightforward to apply.

The theoretical frequency spectrum of a signal $x(t)$ is usually described by its Fourier transform $\mathcal{F}(\omega)$, given by:

$$
\mathcal{H}(\omega)=\int_{-\infty}^{\infty} x(t) e^{-j \omega t} d t
$$

This Fourier spectrum is complex-valued, with an amplitude as well as a phase component. When implemented by Digital Signal Processing, the Fourier spectrum is usually approximated by the discrete Fourier transform, yielding a discrete frequency spectrum.

Let the time signal be denoted by $x(n)=x(n \Delta t)$, with $\Delta t$ the sampling interval. Let this signal be observed by $N$ samples $(n=0 \ldots N-1)$, corresponding to an observation time $T=N . \Delta t$. Then, the discrete Fourier transform (DFT) $X\left(f_{i}\right)$ at frequency $f_{i}$, is defined as:

$$
X\left(f_{i}\right)=\sum_{n=0}^{N-1} x(n) e^{-j 2 \pi f_{i} n \Delta t}
$$

The main characteristics for this approach are that: 
- only spectral results which are an average for the duration T of the observation interval, are obtained.

- the frequency resolution $\Delta f$ of the signal spectrum is limited by the length of the observation window $\left(\Delta f=\frac{1}{T}\right)$.

Essential in the application of the DFT to the spectral analysis of time varying data is that both time and frequency resolution are fixed and independent on the actual signal content or absolute frequency value.

\section{THE WAVELET TRANSFORM}

When recalling the definition of the Fourier transform (1), it can be seen that this formulation actually describes the signal $x(t)$ by means of a set of functions $e^{j \omega t}$, forming a "basis" for signal expansion. These basis functions are continuous and of infinite duration. The spectrum corresponds to the expansion coefficients.

An alternative approach consists of decomposing the data in time-localised wave forms. Such wave forms are usually referred to as Wavelets.

The corresponding Wavelet transformation is then defined $[1,2]$ :

$$
W T(a, \tau)=\frac{1}{\sqrt{|a|}} \int_{-\infty}^{\infty} x(t) \psi\left(\frac{t-\tau}{a}\right) d t
$$

$\psi(t)$ is the basic Wavelet wave form type, the parameter $\tau$ describes the time localisation, the parameter a represents a time-scale parameter. Provided that the basic Wavelet is localised in frequency (for example a time-localised or windowed sinusoid around a frequency $f_{o}$ ), there exists a clear relationship between the scale parameter and an analysis frequency $f=\frac{f_{o}}{a}$ [3]: for different values of $a$, the basic Wavelet is either dilated $(|a|>1)$ or contracted $(|a|<1)$, corresponding to a Wavelet frequency $f_{o} / a$.

An important difference with classical Fourier analysis is that the time and frequency resolution now becomes dependent on this scale factor. For, the time resolution, which is the minimal significant time interval over which evolution can be traced, depends on the "dilatation" of the Wavelet.

For high frequencies $(|a|<1)$, the wave form duration is shorter and thus the time resolution is finer, for low frequencies $(|a|>1)$, the wave form duration is longer, and thus the time resolution is coarser.

The inverse holds true for the frequency resolution: the lower the analysis frequency, the finer the frequency resolution. A comprehensive review on these resolution effects can be found in [3].

The definition of the "basic Wavelet" functions is not unique. Several approaches have been proposed, including orthogonal Wavelets $[1,2,4]$. In view of obtaining physical insight in the signal properties, one interesting Wavelet is the "Gaussian" or "Morlet" Wavelet, defined as [5],

$$
\psi(t)=e^{-j \pi n \frac{t}{T}} \cdot e^{\frac{-t^{2}}{2 T^{2}}}
$$

This Wavelet is in essence a Gaussian modulated sinusoid. This type of Wavelet ensures optimal time-frequency localization. An interesting feature of Gaussian windows is that its Fourier spectrum is also Gaussian. The important parameters in this basic Wavelet are the analysis width $T$ and the constant $n$, which relates the analysis width to the number of sine periods in it $\left(f_{o}=\frac{n}{\tau}\right)$. 
The analysis of the signal spectrum by such Wavelets is essentially equivalent to a constant percentage bandwidth filter analysis $[3,6]$. By selecting appropriate values for $n$, an equivalent to $1 / 1,1 / 3,1 / 12$ or general octave analysis can be devised. This is in contrast to the DFT spectral analysis, which basically corresponds to a constant bandwidth filter analysis.

\section{EXAMPLE: SOUND QUALITY OF A DOOR SLAM}

The sound generated by closing the doors of a car is very important for the customer's subjective quality sensation. For example, the closing door sound of upperclass limousines gives an impression which is automatically associated with a robust, durable high quality car.

In the present case, an unsatisfactory closing door sound was analysed. Objective measures had to be derived to describe the quality, consequently allowing to improve the door closing mechanisms. By comparison with competitor cars, the application of spectral filtering identified the high frequency spectral content to be responsible for the poor sound quality.

Since the sound pressure measured (inside or outside the car) during the door closing is of short duration, and highly non-stationary as well , the first step in addressing the problem is to identify the critical time instances, responsible for the high frequency content.

To this purpose, a short time Fourier transform calculation was performed on the pressure time signal shown in Figure 1 with a high degree of overlap ( $50 \%$ using Hanning windows), and this for different block sizes. The results are shown in Figure 2 for a block size of $16,32,64$, and 128 samples. A higher data size, hence a longer observation window, improves the frequency resolution, but at the same time decreases the time resolution because of the longer "averaging" time. Even for the smallest block size, the high frequency content cannot be localized clearly.
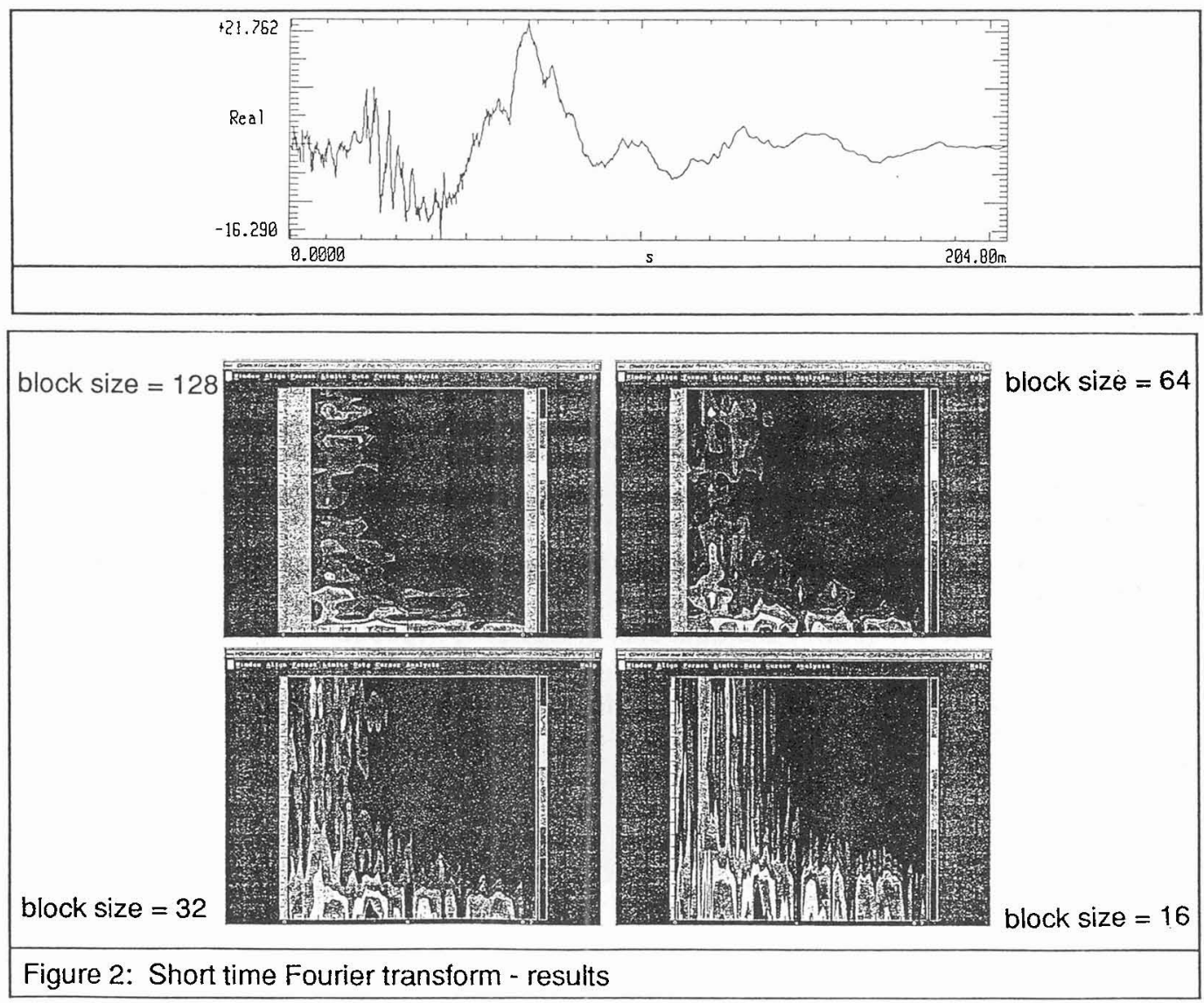
Figure 3 shows the result of a Wavelet transform calculation on the same data. The course time resolution at the low frequencies can be noted, but more important is that the high frequency content clearly occurs at only a few well-defined time instances. A detailed analysis of the mechanics of the lock, supported by a number of acceleration measurements on various parts of the lock, allowed then to identify the various phenomena corresponding to each time instance. The events critical to the sound quality problem appeared to be related to one specific metal-metal cam impact, occurring twice. A modified design applying non-metallic material to that cam solved the problem.

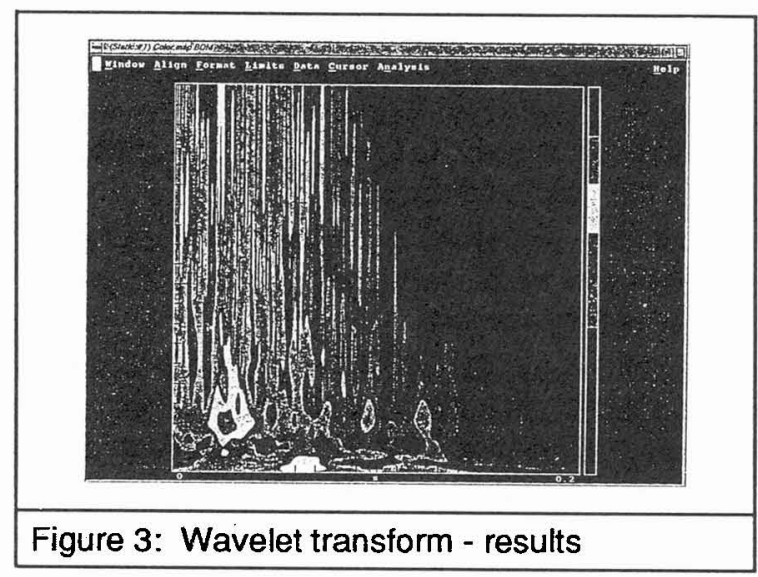

\section{CONCLUSION}

A sound quality problem of a door slam was analysed. Wavelet analysis allowed to identify specific time instances of extremely short duration, with a high frequency content, which allowed to find the physical causes.

\section{ACKNOWLEDGEMENT}

The Wavelet calculation algorithm which was used in the analysis was developed by Technicatome MVI.

\section{REFERENCES}

[1] Daubechies I., Ten Lectures on Wavelets (Society for Industrial and Applied Mathematics, Philadelphia-PA, 1992).

[2] Combes J.M. et al. (eds.), Wavelets (Springer Verlag, Berlin, 1987).

[3] Gram-Hansen K. and Dorize C., "On the Choice of Parameters for Time-Frequency Analysis", Proceedings Congress on Wavelets and their Applications, Marseille, June, 1990.

[4] Rioul O. and Vetterli M., Wavelets and Signal Processing IEEE Signal Processing Magazine 8,4 (1992), pp. 14-38.

[5] Cohen L., "Time-Frequency Distributions, A Review", Proceedings of the IEEE 77,7 July, 1989.

[6] Gram-Hansen K., "A Bandwidth Concept for CPB Time-Frequency Analysis", Proceedings IEEE-ICASSP' 91, Toronto, May 14-17, 1991. 